\title{
Proactive or reactive? Best approach to limb ischemia in peripheral venoarterial extracorporeal life support
}

\author{
Matthew C. Black, MD, and Mark S. Slaughter, MD
}

\author{
From the Department of Cardiovascular and Thoracic Surgery, University of Louisville, Louisville, Ky. \\ Disclosures: Authors have nothing to disclose with regard to commercial support. \\ Received for publication Nov 30, 2015; accepted for publication Nov 30, 2015; available ahead of print Jan 15, \\ 2016. \\ Address for reprints: Mark S. Slaughter, MD, Department of Cardiovascular and Thoracic Surgery, University of \\ Louisville, Louisville, KY (E-mail: mark.slaughter@louisville.edu). \\ J Thorac Cardiovasc Surg 2016;151:1745-6 \\ $0022-5223 / \$ 36.00$ \\ Copyright (C) 2016 by The American Association for Thoracic Surgery \\ http://dx.doi.org/10.1016/j.jtcvs.2015.11.064
}

Since 2007, there has been a rapid and widespread increase in the use of extracorporeal life support (ECLS). ${ }^{1,2}$ Frequently, the clinical scenario is a salvage situation with the hope of restoring normal blood pressure with improved end-organ perfusion to reverse the systemic effects of cardiogenic shock. This emergency treatment strategy gives the patient the chance and time for hemodynamic stabilization allowing at least a "bridge to decision" and, in the best-case scenarios, actual myocardial recovery with the ability to be discharged home. In a recent large series, there was a remarkable 39\% survival to discharge among patients who otherwise had a predicted mortality approaching $100 \% .^{3}$ In this series, as in others, the most frequent and quickest method of establishing ECLS is cannulating a peripheral femoral vein and artery for support or venoarterial ECLS. The concern with cannulation of peripheral vessels, the femoral artery in particular, is the development of lower extremity ischemia. Ipsilateral limb ischemia from arterial occlusion can be found in $13 \%$ to $24 \%$ of patients undergoing peripheral venoarterial ECLS as a result of the cannula size required to achieve adequate supportive flows and the presence of peripheral arterial disease. $^{4-7}$ Many strategies have been proposed to combat this devastating complication. Most of these strategies revolve around decisions for proactive versus reactive placement of antegrade limb perfusion catheters, the method of deployment, and ongoing monitoring of possible inadequate lower extremity perfusion. ${ }^{8-12}$

Vallabhajosyula and colleagues ${ }^{13}$ recently evaluated their program's peripheral venoarterial ECLS outcomes during a 5 -year period in a retrospective study. In this single-center experience, Vallabhajosyula and colleagues ${ }^{13}$ supported 105 patients with venoarterial ECLS and used various strategies for protecting the lower extremity: $35(33 \%)$ received no superficial femoral artery (SFA) antegrade cannulation, $23(21 \%)$ received percutaneous SFA cannulation, and $47(45 \%)$ received an open SFA cannulation. For these antegrade perfusion options, limb ischemia rates were $20 \%$ among patients with no antegrade catheter, 26\% among those with percutaneous antegrade catheter placement,

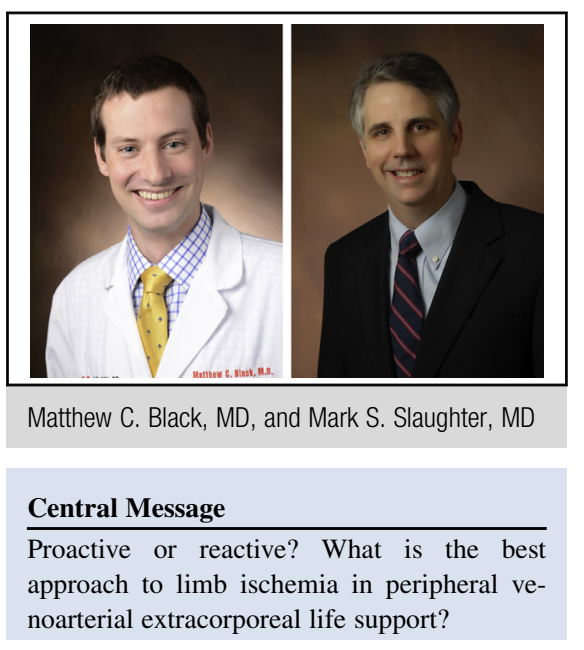

See Article page 1738.

and $2.1 \%$ among those with open antegrade catheter placement. The treatment and technique variability was due to surgeon preference. Overall 30-day survival was $37 \%$, with surprisingly no significant difference among treatment groups.

This study once again highlights the opportunity to save many lives through the emergency use of venoarterial ECLS and adds to the growing literature that recommends a proactive approach to placing a distal perfusion catheter to prevent limb ischemia. As noted, lower extremity limb ischemia can contribute to potential mortality, as has been demonstrated in previous studies, and it adds significant morbidity in patients that survive to decannulation. ${ }^{13,14}$ In addition, supporting the benefits of a proactive approach are the additional risk factors for limb ischemia that include the need for inotropes and vasopressors for cardiovascular support in this critically ill population. A unique finding from this study was the marked difference in outcomes between percutaneously placed distal perfusion catheters and the same catheters placed by an open technique.

The percutaneous approach to antegrade placement resulted in a similar rate of limb ischemia as in patients with no catheter, $26 \%$ versus $20 \%$, which was in sharp contrast to the rate of $2.1 \%$ for an open approach. ${ }^{13}$ Vallabhajosyula and colleagues ${ }^{13}$ reviewed these percutaneous placement cases and found evidence of malposition, posterior vessel injury, hematoma formation, vessel occlusion, and vessel thrombus as reasons for limb ischemia despite 
SFA catheter placement. Subsequently, patients now receive lower extremity angiography of the femoral vessels to confirm correct placement of a percutaneous SFA catheter. During the last year, since the institution of their new placement and imaging algorithm, Vallabhajosyula and colleagues $^{13}$ report no major limb ischemic events necessitating surgical intervention.

This report by Vallabhajosyula and colleagues ${ }^{13}$ is another important contribution that demonstrates the successful outcomes in patients with an otherwise fatal diagnosis and the need for ongoing evaluation to reduce the morbidity and mortality and improve the cost-effectiveness of venoarterial ECLS. As many programs and physicians gain experience, very good results can be obtained with the percutaneous approach for the placement of both the retrograde and antegrade femoral arterial cannulas. ${ }^{10,11}$ Additional monitoring techniques, including perfusion pressure monitoring or near infrared spectroscopy, can be useful tools to assess the adequacy of the distal limb perfusion. ${ }^{12,15}$ If doubt still exists, femoral vessel angiography can be used to verify appropriate catheter placement or other potential artery injury, as demonstrated in this report. A "proactive" approach to prevent limb ischemia is clearly superior to a "reactive" approach. As noted by Moazami and Anandamurthy ${ }^{16}$ in a recent editorial, we have seen "great achievements but still a long road ahead" as we continue to learn how best to use venoarterial ECLS to save the lives of critically ill patients with cardiogenic shock.

\section{References}

1. Gerke AK, Tang F, Cavanaugh JE, Doerschug KC, Polgreen PM. Increased trend in extracorporeal membrane oxygenation use by adults in the United States since 2007. BMC Res Notes. 2015;8:686.

2. Paden ML, Conrad SA, Rycus PT, Thiagarajan RR. ELSO Registry. Extracorporeal Life Support Organization Registry Report 2012. ASAIO J. 2013;59:202-10.
3. Truby L, Mundy L, Kalesan B, Kirtane A, Colombo PC, Takeda K, et al. Contemporary outcomes of venoarterial extracorporeal membrane oxygenation for refractory cardiogenic shock at a large tertiary care center. ASAIO J. 2015;61:403-9.

4. Biočina B, Petričević M, Belina D, Gašparović $\mathrm{H}$, Svetina L, Konosić S, et al. Results of extracorporeal life support implementation in routine clinical practice: single center experience. Croat Med J. 2014;55:600-8.

5. Combes A, Leprince P, Luyt CE, Bonnet N, Trouillet JL, Léger P, et al. Outcomes and long-term quality-of-life of patients supported by extracorporeal membrane oxygenation for refractory cardiogenic shock. Crit Care Med. 2008;36:1404-11.

6. Doll N, Kiaii B, Borger M, Bucerius J, Krämer K, Schmitt DV, et al. Five-year results of 219 consecutive patients treated with extracorporeal membrane oxygenation for refractory postoperative cardiogenic shock. Ann Thorac Surg. 2004; 77:151-7; discussion 157.

7. Papadopoulos N, Marinos S, El-Sayed Ahmad A, Keller H, Meybohm P, Zacharowski K, et al. Risk factors associated with adverse outcome following extracorporeal life support: analysis from 360 consecutive patients. Perfusion. 2015;30:284-90.

8. Foley PJ, Morris RJ, Woo EY, Acker MA, Wang GJ, Fairman RM, et al. Limb ischemia during femoral cannulation for cardiopulmonary support. J Vasc Surg. 2010;52:850-3.

9. Huang SC, Yu HY, Ko WJ, Chen YS. Pressure criterion for placement of distal perfusion catheter to prevent limb ischemia during adult extracorporeal life support. J Thorac Cardiovasc Surg. 2004;128:776-7.

10. Lamb KM, Hirose H, Cavarocchi NC. Preparation and technical considerations for percutaneous cannulation for veno-arterial extracorporeal membrane oxygenation. J Card Surg. 2013;28:190-2.

11. Spurlock DJ, Toomasian JM, Romano MA, Cooley E, Bartlett RH, Haft JW, et al. A simple technique to prevent limb ischemia during veno-arterial ECMO using the femoral artery: the posterior tibial approach. Perfusion. 2012;27:141-5.

12. Steffen RJ, Sale S, Anandamurthy B, Cruz VB, Grady PM, Soltesz EG, et al. Using near-infrared spectroscopy to monitor lower extremities in patients on venoarterial extracorporeal membrane oxygenation. Ann Thorac Surg. 2014;98: 1853-4.

13. Vallabhajosyula P, Kramer M, Lazar S, McCarthy F, Rame E, Wald J, et al. Lower extremity complications with femoral extracorporeal life support. J Thorac Cardiovasc Surg. 2016;151:1738-44.

14. Hei F, Lou S, Li J, Yu K, Liu J, Feng Z, et al. Five-year results of 121 consecutive patients treated with extracorporeal membrane oxygenation at Fu Wai Hospital. Artif Organs. 2011;35:572-8.

15. Wong JK, Smith TN, Pitcher HT, Hirose H, Cavarocchi NC. Cerebral and lower limb near-infrared spectroscopy in adults on extracorporeal membrane oxygenation. Artif Organs. 2012;36:659-67.

16. Moazami N, Anandamurthy B. Acute circulatory support with ECMO: great achievements but still a long road ahead. ASAIO J. 2015;61:371-2. 